\title{
Acediasulfone Sodium
}

National Cancer Institute

\section{Source}

National Cancer Institute. Acediasulfone Sodium. NCI Thesaurus. Code C72587.

A sodium salt form of acediasulfone, a long-acting prodrug of dapsone, used in the treatment of leprosy. 